\title{
The relationship between inhibition of automatic imitation and personal cognitive styles
}

\author{
Yuki Nishimura ${ }^{1,2^{*}}$ (D), Yuki Ikeda ${ }^{1,2}$ and Shigekazu Higuchi ${ }^{3}$
}

\begin{abstract}
Background: Previous studies have demonstrated the importance of the inhibition of automatic imitation in social interactions. Additionally, cognitive traits are known to vary among individuals. According to the empathizingsystemizing (E-S) model, personality can be quantified by empathizing and systemizing drives in causal cognition. Since inhibition of automatic imitation is strongly related to social cognition, the level of inhibition may be explained by personal cognitive traits. Thus, the current study tested whether cognitive traits, measured based on the E-S model, correlated with levels of automatic imitation inhibition.

Methods: The empathizing-systemizing quotient (EQ-SQ) questionnaire was used to assess cognitive traits. Behavioral and electroencephalogram data were acquired during the imitation inhibition task. In addition to reaction time, based on signal detection theory, task sensitivity and response bias were calculated from reaction data. As a physiological measure of automatic imitation, mu rhythm power suppression was calculated from electroencephalogram data. Congruency effects for reaction time and electroencephalogram measures were calculated by subtracting congruent trials from incongruent trails.
\end{abstract}

Results: Correlation analyses between cognitive traits and task measures were conducted. There was a negative correlation found between EQ score and the behavioral index reflecting task performance. Moreover, a negative correlation was found between SQ score and the congruency effect on mu suppression.

Conclusions: Participants with higher EQ scored relatively lower in inhibiting their responses. Conversely, high SQ participants showed successful inhibition of mu suppression. The imitative tendency may disturb the inhibition of response. The correlation between SQ and mu index suggests the involvement of domain-general information processing on imitation inhibition; however, further research is required to determine this. Since different correlations were found for behavioral and physiological measures, these measures may reflect different steps of information processing for successful task execution. Through correlational analysis, a possible relation was identified between the inhibiting process of automatic imitation and personal cognitive styles on social interactions.

Keywords: Imitation inhibition, Personal cognitive traits, Mirror neuron system, Mu rhythm suppression

\footnotetext{
* Correspondence: y.nishimura.941@s.kyushu-u.ac.jp

${ }^{1}$ Graduate School of Integrated Frontier Sciences, Kyushu University, 4-9-1

Shiobaru, Minami-ku, Fukuoka 8158540, Japan

${ }^{2}$ Research Fellow of the Japan Society for the Promotion of Science, 4-9-1

Shiobaru, Minami-ku, Fukuoka 8158540, Japan

Full list of author information is available at the end of the article
}

(c) The Author(s). 2018 Open Access This article is distributed under the terms of the Creative Commons Attribution 4.0 International License (http://creativecommons.org/licenses/by/4.0/), which permits unrestricted use, distribution, and reproduction in any medium, provided you give appropriate credit to the original author(s) and the source, provide a link to the Creative Commons license, and indicate if changes were made. The Creative Commons Public Domain Dedication waiver (http://creativecommons.org/publicdomain/zero/1.0/) applies to the data made available in this article, unless otherwise stated. 


\section{Background}

Throughout human evolution, cooperation (and resultant society building) has been selected for ultimately increasing the species' chances of survival. As a social animal, it has been suggested that humans possess enhanced social cognitive abilities compared to any other creature [1]. Of these abilities, empathy is likely one of the most important, not only for the creation of societies, but also for the acquisition of motor skills [2-4]. Automatic imitation is one of the core functions of empathy. The neural basis of imitation is the mirror neuron system (MNS) [5, 6]. The MNS is a brain system first found in monkeys, which activates during both the performance and observation of a body action [5, 7-9]. A number of brain imaging and single-cell recoding studies have also demonstrated the existence of an MNS in humans [10-13]. It is thought that automatic imitation is one kind of stimulus-response compatibility that is acquired during development [14-16]. Several experiments and meta-analyses have shown that suppression of electroencephalogram (EEG) sensory-motor mu wave possibly reflects MNS activity, as mu wave power is suppressed by both the execution and observation of an action [17-21]. Especially, hand movements have a pronounced effect on imitative brain response measured by mu suppression [18, 22]. Moreover, spontaneous recording of fMRI and EEG have shown that mu wave reduction is one reliable measure of MNS activity [17, 21, 23].

Although automatic imitation, supported by the MNS, is a core function of social interaction, imitation is obviously not always the most appropriate reaction in daily life. Inhibition of imitative behavior is important for the facilitation of smooth complementary and joint actions. Therefore, in some cases, mirroring may be counterproductive [24-27]. For example, while handing a cup from one person to another, or while playing catch, the receiver should inhibit his/her imitative motor action and prepare an appropriate response. Furthermore, not only the actual imitation but also the in-brain imitation must be inhibited in the same manner for successful interaction. There is an ongoing debate as to which brain network is responsible for controlling automatic imitation. Initially, "social brain" regions, related to theory of mind, were found to be active during an imitation inhibition task. Brass et al. investigated the inhibitory system of imitative response tendencies and reported several brain regions involved in inhibition, including the temporal parietal junction, dorsolateral prefrontal cortex, right frontopolar cortex, right anterior parietal cortex, and precuneus [25, 28]. More recently, a domain-general brain network related to broad reaction-inhibition has also been implicated in imitation inhibition [29]. The imitation-inhibition task is designed to evaluate the level of inhibition of imitative tendencies [28]. It has been adopted in a number of studies to test the conditional or individual ability to inhibit the imitative response [25, 26, 28-34].

According to Decety and Svetlova, empathy is a complex construct consisting of both emotional and cognitive elements [2]. Furthermore, there has been an attempt to quantify human personality from causal cognition. Baron-Cohen developed the empathizing-systemizing (E-S) model to explain individual cognitive traits from two psychological "drives" [35]. Empathizing is a drive that identifies other's emotions or thoughts and causes an individual to react with an appropriate emotion by analyzing psychological causal relations. By contrast, systemizing is a drive that analyzes factors of systems and derives basic patterns, which defy the function of the system. The term "system" here covers all processes, from physical law to social phenomenon, which have any kind of law-like nature [35, 36]. The Empathizing-Systemizing Quotient (EQ-SQ) questionnaire was developed to measure these constructs [37, 38].

Variation between individuals is known to exist in imitation-inhibition task performance and EQ-SQ score, both of which are thought to reflect social interactive skills. However, no study has aimed to address the relationship between an individual's cognitive style (as assessed via the EQ-SQ questionnaire) and adaptive imitation-inhibition performance, despite both being closely related to social cognition and interaction in daily life and both possibly originating from higher order frontal brain functions. By investigating the relationship between personal cognitive traits assessed by the self-completion questionnaire and the performance of inhibition of automatic imitation, we aimed to deepen understanding of the involvement of the inhibiting process of automatic imitation in forming in individual's traits related to social interaction.

To accomplish this, participants were asked to respond by lifting up either the index or middle finger, according to the task indicator and hand movement stimuli presented on the screen. Reaction time (RT), task sensitivity, and response bias were collected as behavioral measures and event-related mu wave desynchronization (ERD) of EEG was measured to determine imitating MNS activity and its modulation. We used indices from signal detection theory (SDT) instead of the classical proportion of correct answers. By using SDT measures, participant's task performance $\left(d^{\prime}\right)$ is estimated independently from their response bias $(C)$ [39-41]. We hypothesized that participants with a high EQ would show better performance on the task and successful inhibition of imitative brain activity.

\section{Methods}

\section{Participants}

Twenty-six young adults participated in the study (15 male, 11 female; mean age $23.2 \pm 1.25$ years). All participants were right-handed, as confirmed by an Edinburgh Handedness inventory (min-max 70-100; median 
84.12). Participants were naïve as to the purpose of the experiment and were informed before the study that their privacy would be secured. Written informed consent was provided by the participants prior to the commencement of the experiment, and participants were debriefed following experiment completion.

The procedure of the study was approved by the Ethics Committee of Kyushu University. The study was conducted according to the principles of the Declaration of Helsinki.

\section{Equipment}

The study was conducted in an acoustically and electrically sealed room located in Kyushu University. A 64-channnel EEG was recorded using an EEG amplifier (Net Amps 200, EGI) with sensor-net (HCGSN-64, EGI). Electrode impedance was maintained to remain under $50 \mathrm{k} \Omega$ as suggested by the manufacturer. EEG data were filtered in real time by the amplifier hardware, with the filter set to $0.01 \mathrm{~Hz}$ high-pass and $200 \mathrm{~Hz}$ low-pass, and digitized at $500 \mathrm{~Hz}$. Stimuli were delivered with Presentation Ver. 20.0 (NBS Inc.) and an LCD display (E2351VR-BN, LG Electronics) refreshing at $60 \mathrm{~Hz}$. Participants reaction (finger lifting) was acquired by capacitance sensor (AD00019, Bit Trade One, LTD.) connected to the Presentation software.

\section{Imitation-inhibition task}

The task utilized in the current study was based on a task developed and used in previous research [42]. Participants were required to respond as soon as possible according to simultaneously displayed finger movement and instructions (congruent or incongruent; Fig. 1). The presented stimuli consisted of a short movie of a hand quickly lifting either an index or middle finger, and a surrounding colored frame (red or green) indicating a response by the congruent or incongruent finger. The assignment of colors to the tasks (congruent or incongruent) was counter balanced among the participants. For example, if the index finger was lifted in the stimuli and the colored frame indicated an incongruent response, the correct response for the participant was lifting their middle finger.

In addition to the imitation condition described above, a spatial condition, in which one of two black-dots moved upwards, was tested to take the spatial compatibility aspect into account. The order of the conditions was counter balanced.

The task was divided into three blocks, including a randomization of trials, in which half were congruent and the other half were incongruent. This was done so that participants could not predict the next task instruction (total 300 trials per condition; 75 trials each for congruent index finger, congruent-middle finger, incongruent index finger, and incongruent middle finger).

\section{Behavioral measurements and analysis}

Reaction time (RT) was calculated for each task instruction (congruent or incongruent) of each condition (imitation or spatial). In order to highlight the congruency-effect, $\Delta \mathrm{RT}$ was calculated by subtracting the mean RT of congruent trials from the mean RT of incongruent trials for each condition.

Based on signal detection theory (SDT), task sensitivity index $\left(d^{\prime}\right)$, and response bias $(C)$ were calculated as performance indices. SDT assumes that, in an uncertain condition, participants are active decision makers who make difficult perceptual judgements. The SDT index, rather than the percent of correct responses, provides effective solutions to differentiate participants' response tendencies (bias) from the ability to detect and discriminate information (task sensitivity) [39-41]. We calculated

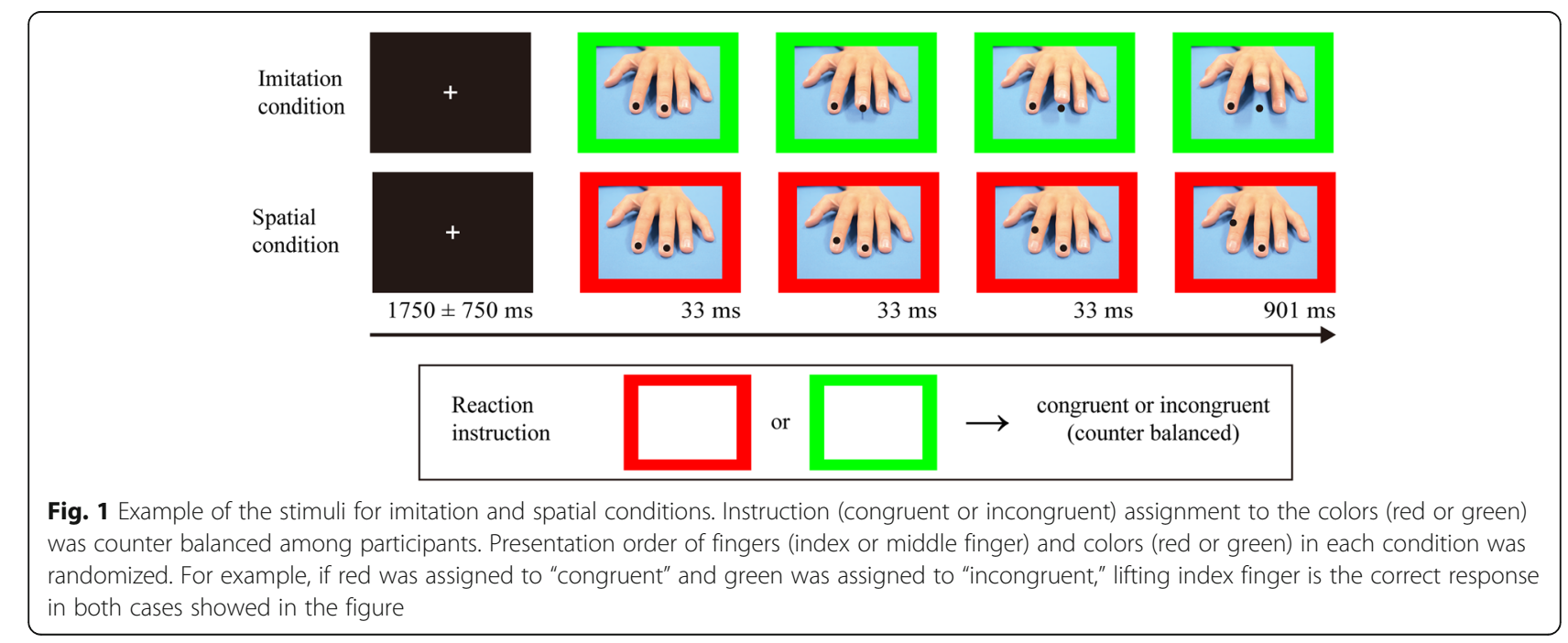


sensitivity and bias by categorizing congruent success, congruent failure, incongruent failure, and incongruent success as hit, miss, false alarm, and correct rejection, respectively. A higher $d^{\prime}$ indicates higher task performance. The response bias index $(C)$ is zero when there is no bias at all. This variable would take a positive value when responses are biased toward incongruent responses, and vice versa. Formulas for $d^{\prime}$ and $C$ are the following:

$$
\begin{aligned}
& d^{\prime}=Z_{\text {hit }}-Z_{\text {false alarm }} \\
& C=-0.5 \times\left[Z_{\text {hit }}+Z_{\text {false alarm }}\right]
\end{aligned}
$$

where, $Z_{\text {hit }}$ is the $z$-transformed hit rate [hit count/(hit count + miss count)] and $Z_{\text {false alarm }}$ is the $z$ transformed false alarm rate [false alarm count/(correct rejection count + false alarm count)].

\section{EEG measurements and analysis}

As an index of automatic imitation, mu wave event-related desynchronization (ERD) measured around central sulcus was acquired. In addition to mu ERD, alpha ERD possibly reflecting the attention level was calculated from the occipital sites, in order to take alpha wave contamination to the mu ERD into account. All EEG preprocessing and analysis was carried out using EEGLAB 14.1.1b [43], which is an open source toolbox of MATLAB (MathWorks Inc.). Raw EEG data, following manual rejection of bad channels, were filtered by FIR band-pass filter $(0.5-40 \mathrm{~Hz}$; transition band width $1 \mathrm{~Hz})$ and epoched according to stimuli onset. Furthermore, bad epochs found in the data were automatically rejected according to joint probability of the data (both single-channel and all-channel threshold were set to 3 S.D). Following this, all data were re-referenced to the average. While data were re-referenced, outer electrodes (e.g., facial electrodes) were excluded from calculations (channels 23, 55, and $61 \sim 64$ ). Two participants were excluded from further analysis due to an insufficient number of epochs. Preprocessed data were then sent to infomax independent component analysis (ICA). Independent components representing eye-blinks or eye-movement were manually rejected based on the topographical map, frequency spectrum, and activation synchrony with electrooculography (EOG).

ERD was calculated by EEGLAB's time-frequency analysis function. First, event-related spectrum perturbations were calculated by wavelet analysis, starting with 2 cycles and increasing by 0.5 cycles toward higher frequencies. Second, mu wave $(8-13 \mathrm{~Hz})$ power from $300 \mathrm{~ms}$ to $600 \mathrm{~ms}$ after the event onset was calculated for each participant in decibel, according to the baseline period, which was $200 \mathrm{~ms}$ to $0 \mathrm{~ms}$ prior to the event onset. Finally, ERDs from each channel were averaged across the regions of interest (ROIs) to improve the reliability of the data. The left central (LC) region, representing mu ERD, was covered by $\mathrm{C} 3$ and its neighboring channels (i.e., 15, 16, 20, 21, and 22). The mid occipital (MO) region, representing alpha ERD, was covered by $\mathrm{Oz}$ and its neighboring channels (i.e., 35, 37, and 39; Fig. 2). After calculating ERDs, a congruency effect for mu and alpha ERDs was calculated in the same manner as $\Delta \mathrm{RT}$.

\section{Statistical analyses}

In order to test the relationship between the task performance and the EQ-SQ scores, Spearman's rank correlation was calculated. A Bonferroni correction was used to adjust the $p$ value for multiple tests. To highlight the effect of task and personal cognitive traits, an additional mixed-design analysis of variance (ANOVA) was conducted on data that showed significant correlations. The factors included in ANOVAs were high and low groups of $\mathrm{EQ}$ or $\mathrm{SQ}$, and indicated tasks (congruent and incongruent). High EQ or SQ groups contained the upper 33\% of participants and low EQ or SQ groups consisted of the lower $33 \%$ of participants. An independent $t$ test was conducted to test the shift of response bias. All results are reported using an $\alpha$ of $p<0.05$. All statistical tests were conducted using R version 3.5.1 [44].

\section{Results}

\section{EQ-SQ score}

EQ and SQ distribution of the participants are shown in Fig. 3. Both $\mathrm{EQ}$ and $\mathrm{SQ}$ varied widely (median $=29,29$; $\min =7,16 ; \max =58,64$; for $E Q$ and $S Q$, respectively). No correlation was found between these two scores $($ rho $=$ 0.333, $n=25, p=0.103$ ).

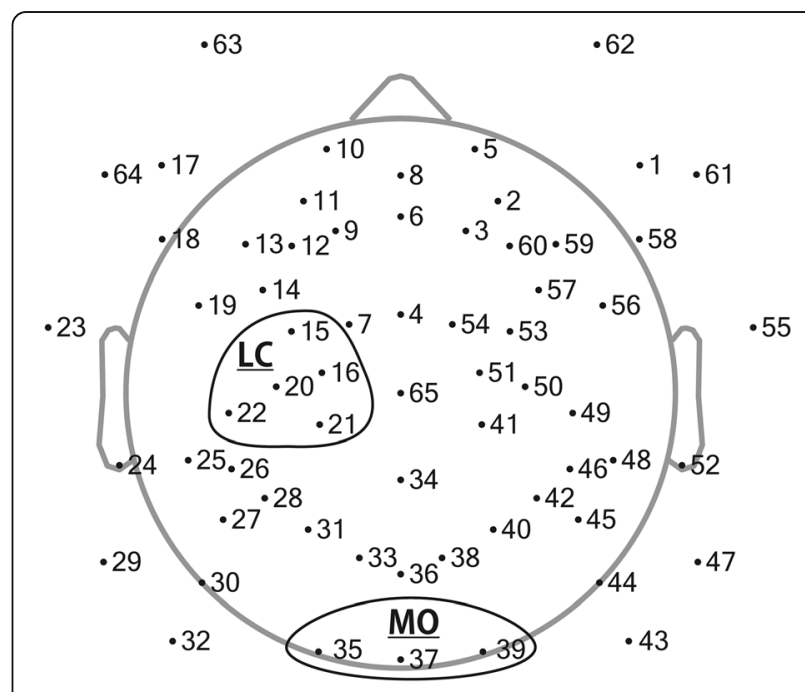

Fig. 2 Channel location of the EEG sensor net. Each dot represents 1 of 65 channels. Channels included in the ROls are circled 

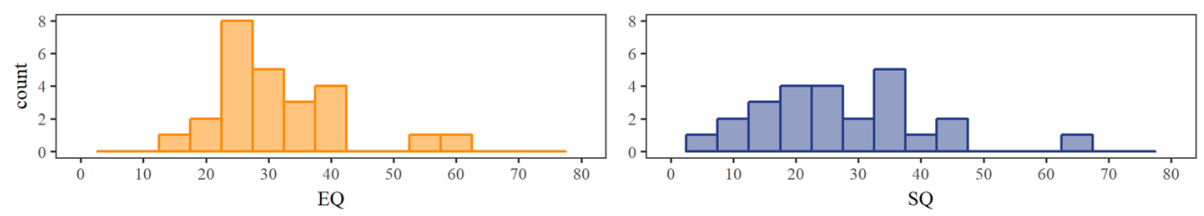

Fig. 3 Histogram of EQ and SQ score distribution. Correlation analysis found no correlation between these scores (rho $=0.333, n=25, p=0.103)$

\section{Behavioral measures}

Figure 4 shows the distribution of $\Delta \mathrm{RT}, d$, and $C$ for each condition. Generally, RT for the incongruent trials was slower than that of congruent trials, similar to results reported in earlier studies [26]. Although task sensitivity $\left(d^{\prime}\right)$ was generally high, it ranged from nearly 2 to 5. A one sample $t$ test showed that response biases $(C)$ were shifted toward a positive value, indicating that reactions were biased toward incongruent reactions in both the imitation and spatial conditions $[t(24)=24.582$, $p<0.001 ; t(24)=24.773, p<0.001$, respectively].

The results of a Spearman's correlation test for the behavioral indices are shown in Table 1. In opposition to our hypothesis, negative correlations between EQ and $\triangle \mathrm{RT}$ in the imitation condition and between EQ and $d$ ' in the spatial condition were found, although the $p$ values did not reach statistical significance after Bonferroni correction.

A supplemental ANOVA on RT measured at imitation condition with task (congruent and incongruent) and EQ group (high and low) as factors revealed a significant main effect of task $\left[F(1,17)=10.605, p=0.005, \eta_{\mathrm{p}}{ }^{2}=0.384\right]$ indicating prolonged RT in incongruent trials, and an interaction of the two factors $[F(1,17)=4.785, p=0.043$, $\left.\eta_{\mathrm{p}}{ }^{2}=0.220\right]$. Post hoc tests on the interaction showed a significant simple main effect of task for the low EQ group $\left[F(1,9)=14.680, p=0.004, \eta_{\mathrm{p}}{ }^{2}=0.620\right]$ indicating shorter RT in the congruent trials. On the other hand, there were no RT differences in the high EQ group $\left[F(1,8)=0.586, p=0.466, \eta_{\mathrm{p}}{ }^{2}=0.068\right]$. As illustrated in Fig. 5, smaller $\Delta \mathrm{RT}$ in participants with higher EQ originated from slower RT in the congruent trials. There were no significant correlations found between SQ and behavioral indices.

\section{Physiological measures}

Grand averaged $\mathrm{mu}$ and alpha ERD waveforms are shown in Fig. 6. The distribution of $\triangle \mathrm{ERD}$ measured over the LC (mu ERD) and MO (alpha ERD) are shown in Fig. 7. Higher $\triangle \mathrm{mu}$ ERD indicates a more successful inhibition of MNS activity during incongruent trials. Conversely, negative values of $\triangle \mathrm{mu}$ ERD indicate greater inhibition of MNS activity during congruent trials. All $\triangle E R D$ are distributed from positive to negative values.

The correlation analysis conducted on $\triangle E R D$ revealed a positive correlation between $\mathrm{SQ}$ and $\triangle \mathrm{mu}$ ERD in the imitation condition (Table 1). An additional ANOVA on ERD measured at LC in the imitation condition with task (congruent and incongruent) and SQ-group (high and low) as factors was conducted. As a result, a significant interaction of the two factors was found $[F(1,16)=6.266, p=$ $\left.0.024, \eta_{\mathrm{p}}{ }^{2}=0.281\right]$. Post hoc analysis on the interaction showed a significant simple main effect of task for the low-SQ group indicating greater mu suppression in the incongruent trial $\left[F(1,8)=6.247, p=0.037, \quad \eta_{\mathrm{p}}{ }^{2}=0.439\right]$

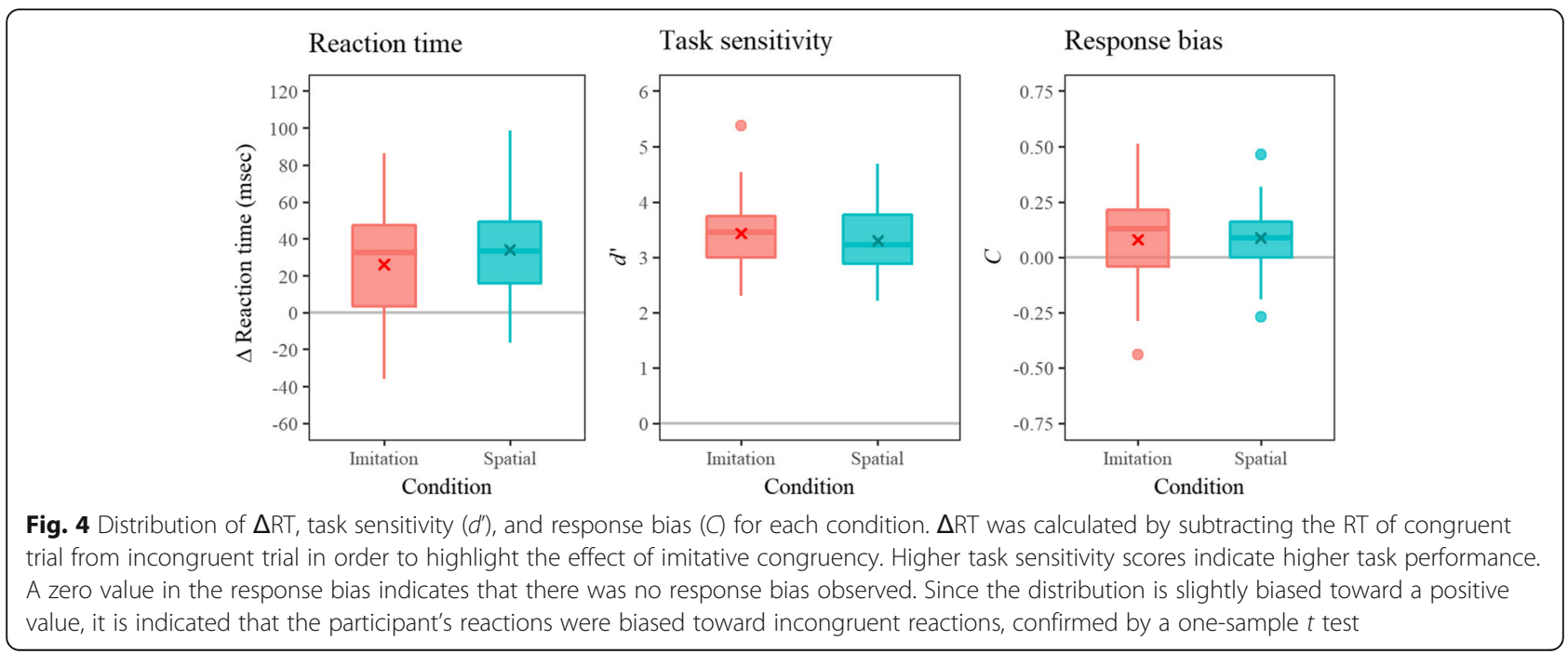


Table 1 Correlation results for behavioral measures

\begin{tabular}{|c|c|c|c|c|c|}
\hline \multirow[t]{2}{*}{ Condition } & \multirow[t]{2}{*}{ Index } & \multicolumn{2}{|l|}{$\mathrm{EQ}$} & \multicolumn{2}{|l|}{ SQ } \\
\hline & & rho & $P_{\text {corrected }}$ & rho & $P_{\text {corrected }}$ \\
\hline \multirow[t]{3}{*}{ Imitation } & $\Delta R T$ & -0.43 & $0.06+$ & 0.07 & 1.00 \\
\hline & $d^{\prime}$ & -0.20 & 0.68 & -0.25 & 0.45 \\
\hline & $C$ & 0.06 & 1.00 & -0.27 & 0.37 \\
\hline \multirow[t]{3}{*}{ Spatial } & $\Delta R T$ & -0.29 & 0.31 & 0.04 & 1.00 \\
\hline & $d^{\prime}$ & -0.43 & $0.06+$ & -0.20 & 0.69 \\
\hline & C & 0.27 & 0.40 & -0.37 & 0.13 \\
\hline
\end{tabular}

Spearman's rank correlation test

$n=24$; Bonferroni corrected: $\dagger$ for $P_{\text {corrected }}<0.1$

(Fig. 8). No significant correlation was found between EQ and $\triangle E R D s$. In addition, there were no significant correlations found in the spatial condition (Table 2).

\section{Discussion}

In order to reveal the involvement of inhibition of imitation on formation of personal cognitive traits, we tested the relationship between personal cognitive traits, and performance on an imitation inhibition task, as measured by behavioral and physiological indices. In the imitation condition, a negative correlation was observed between EQ and $\triangle \mathrm{RT}$, although $p$ values did not reach statistical significance following Bonferroni correction. Moreover, a positive correlation was observed between SQ and the congruency effect, as calculated from the mu ERD, which is an EEG index of MNS activity. These correlations were specific to the imitation condition, thus the corresponding correlations in the spatial condition were not significant. In the spatial condition, which was set to take the spatial compatibility effect into account, a trend of correlation between EQ and $d$ ', which
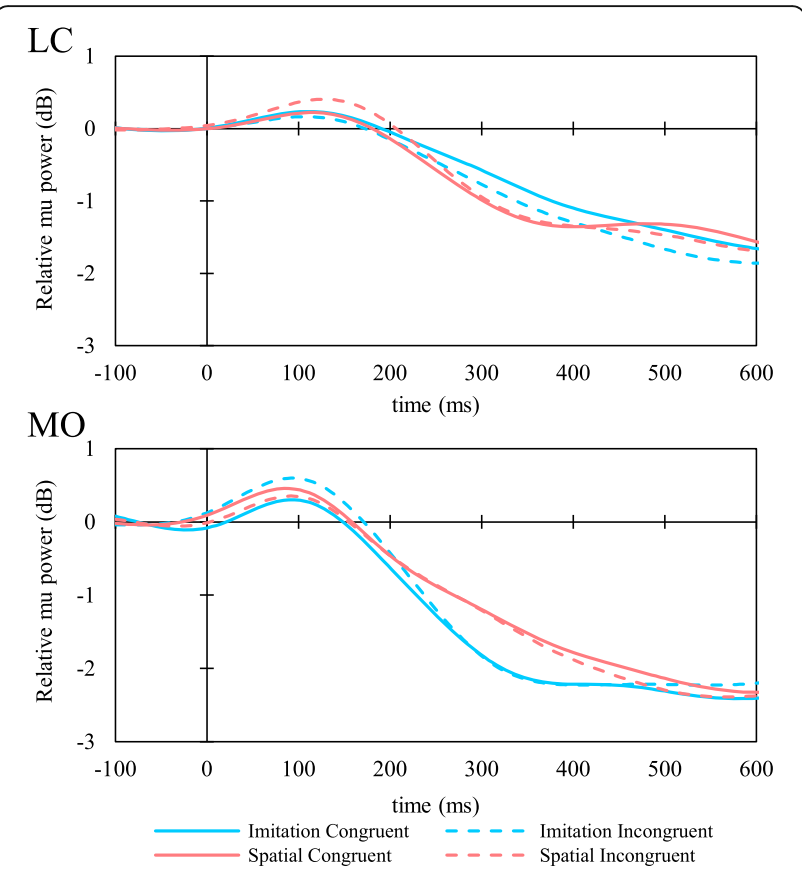

Fig. 6 Grand average of mu and alpha ERDs measured at ROls (LC and $\mathrm{MO})$, respectively. Red lines represent imitation condition and blue lines represent spatial condition. Solid lines represent congruent trials and dotted lines represent incongruent trials for each condition

was specific to this spatial condition, was found. No correlation was found for $\triangle E R D$.

The $\Delta R T$ of the imitation condition showed a trend of negative correlations with EQ after the correction of multiple tests. A smaller $\Delta \mathrm{RT}$ can be interpreted as a diminished congruency effect, which can further be interpreted as higher task performance. Nevertheless, in the current study, smaller $\Delta \mathrm{RTs}$ originated from prolonged RTs in the congruent trials in high-EQ participants,
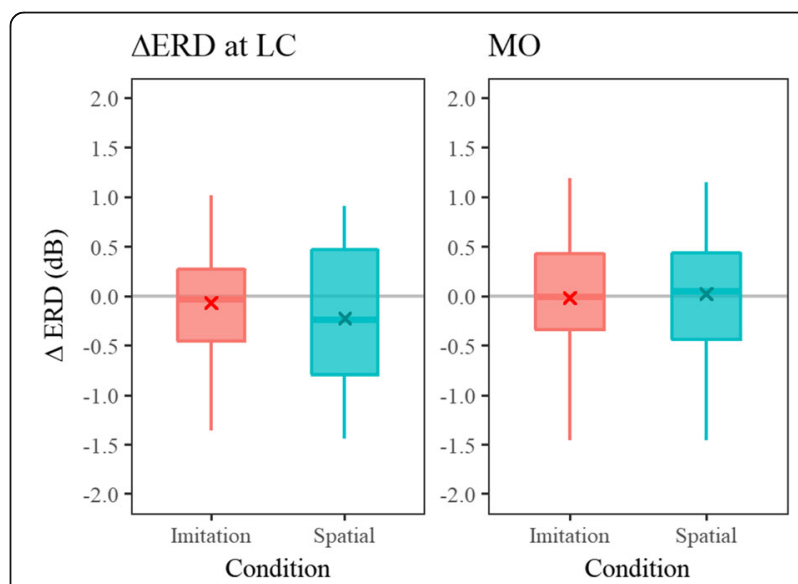

Fig. 7 The observed congruency effect on mu and alpha ERD for each condition. Higher values of $\triangle E R D$ indicate greater activity during the incongruent trials compared to the congruent trials and vice versa 
mu ERD at imitation cond.

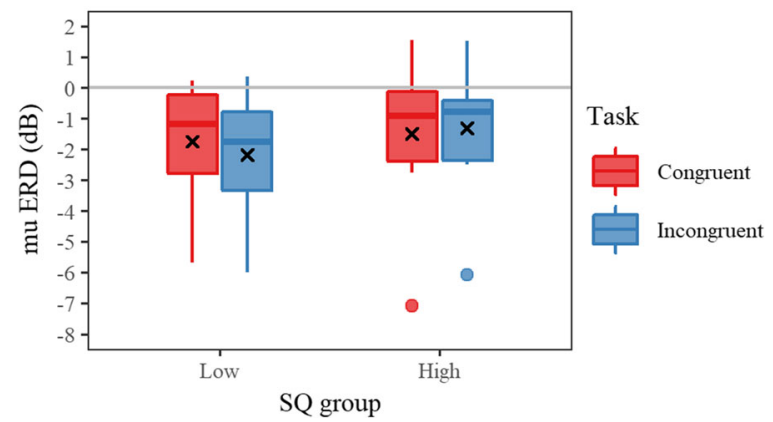

Fig. 8 The mu ERD at imitation condition for low and high SQ groups. Red and blue box represents reaction time of congruent and

incongruent trial, respectively. The greater ERD (more negative value) indicates greater sensory-motor activation including automatic imitation. The post hoc test following the ANOVA showed significant simple main effect of task for the low SQ group, indicating greater mu ERD at incongruent trials only for the low SQ group

suggesting that they took longer to respond in both congruent and incongruent trials. Therefore, higher empathic cognitive traits may lead to poorer imitation inhibition performance. From the related early research, it is known that the amount of unconscious imitation is influenced by the amount of rapport feeling [45, 46]. Moreover, one study, which primed participants either pro- or non-socially and compared the congruency effect, found that pro-socially primed adults showed a larger compatibility effect in an imitation task [47]. Later research also confirmed the effect of priming, especially in adults compared to adolescents (mean ages around 27 and 13 years, respectively) [48]. As such, higher empathic traits may disturb smooth selection (resulting in poorer reaction time) during the imitation inhibition task. Meanwhile, both empathic traits and higher imitation-inhibition ability are often associated with higher social ability and/or successful interactions $[5,9,49]$. Since the correlation found was negative, the current results suggest that a relationship exists between empathic cognitive traits and task performance but not in a direct manner. Further study is required to reveal the causal relationship related to this point.

Table 2 Correlation results for EEG measures

\begin{tabular}{lllllll}
\hline Condition & ROI & & EQ & & & SQ \\
\cline { 3 - 4 } \cline { 6 - 7 } & & rho & $P_{\text {corrected }}$ & & rho & $P_{\text {corrected }}$ \\
\hline Imitation & LC & 0.22 & 0.58 & & 0.46 & $0.04^{*}$ \\
& MO & -0.16 & 0.88 & & -0.02 & 1.00 \\
\multirow{2}{*}{ Spatial } & LC & -0.20 & 0.69 & & -0.11 & 1.00 \\
& MO & -0.12 & 1.00 & & -0.01 & 1.00 \\
\hline
\end{tabular}

Spearman's rank correlation test. $R O I$ region of interest; $L C$ left central; $M O$ mid occipital. $n=25$; Bonferroni corrected: * for $P_{\text {corrected }}<0.05$
The current study is the first to apply SDT to investigate the inhibition of automatic imitation. A number of earlier studies have used $\Delta \mathrm{RT}$ to highlight the congruency effect of behavioral measures [26, 28, 33]. Compared to reaction time, error rate is less likely to reflect the effect. Conversely, nominal data contains important information on participants' performance, especially when data is analyzed based on SDT [39-41]. In the current study, the performance index $d^{\prime}$ at spatial condition showed a trend of correlation, yet response bias (i.e., a shift of decision criterion) did not. No correlations were found between EQ-SQ scores and SDT measures of the imitation condition. Meanwhile, we found that their response was biased toward the incongruent responses by analyzing SDT measures. It was indicated that the participants were more prepared for incongruent responses, which required more completed information processing $[28,33,50,51]$. In this study, we could not find any evidence of a relationship between personal cognitive traits and an individual's task sensitivity or response bias in the imitation condition. However, the use of SDT measures may still provide deeper insights for behavioral data in future research, such as the significant response bias found in the current study. In addition, task sensitivity in the spatial condition showed a marginal negative correlation with EQ score. This suggests poorer task sensitivity in participants who have a higher tendency toward empathic cognitions. Although the correlation was not hypothesized and did not reach significance, a relationship may exist between the processing of spatial compatibility generated by the stimuli we used and the empathizing score.

In imitation inhibition tasks, behavioral measures can be defined as the final output of information processing. Thereby, we focused on EEG mu power suppression related to the observation of action of others. By measuring in-brain action mirroring through the widely used mu ERD [17, 52, 53], we assessed the congruency effect at a lower level of information processing. As a result, there was a significant positive correlation found between $\triangle \mathrm{mu}$ ERD and SQ scores. However, no correlation between $\triangle \mathrm{mu}$ ERD and EQ was found. This suggests that participants with higher SQ scores were able to modulate mu suppression during incongruent trials, while individuals with lower SQ scores showed greater MNS activity in incongruent, compared to congruent, trials. Thus, task strategy may differ between individuals with lower and higher SQ scores; however, further study of this possibility is required. There were no correlations found in spatial condition. This suggests that the congruency effect observed in the imitation condition was likely originated from the process of automatic imitation activated by the presence of biological motion in the stimuli, not from the actual finger movement. 
Notably, there were no significant correlations found for $\triangle$ alpha ERD, indicating that personal traits were only correlated with congruency effects observed in sensory motor $\mathrm{mu}$ rhythms and not in the occipital alpha rhythm. Moreover, no significant correlation was found for the spatial condition. While the required response was exactly the same among conditions, absence of the biological motion was the factor controlled between the two conditions. This result implies that not the ability of handling spatial compatibility, but rather the ability of dealing with biological incompatibility, is correlated with the personal cognitive traits measured by the EQ-SQ questionnaire.

Measures of $\triangle \mathrm{mu}$ ERD showed significant correlations with SQ scores, while behavioral measures showed significant correlations with EQ scores. Although EQ and SQ scores are known to be moderately correlated, each score is designed to represent an independent aspect of cognition [35, 36, 54]. In addition, in the current study, no correlation was found between the two scores. As was discussed earlier, if it is assumed that a behavioral measure is the final outcome of information processing flow for the inhibition task, the mirroring activity and its inhibitory control would be placed at relatively earlier steps. Therefore, the behavioral and physiological indices may reflect different levels of processing for the inhibition of automatic imitation. According to the associative sequence learning model, automatic imitation is mediated by low-level mechanisms $[14,55,56]$. While behavioral measures reflect the whole process, the congruency effect on ERDs (i.e., $\triangle$ ERDs) may reflect not only the level of imitation inhibition facilitated by higher order brain function, but also the lower level processing of observed action. In other words, not only empathic cognitive function, but also the systemizing aspect of the cognitive ability of social cognition plays an important role in successful task execution. A number of studies using fMRI to determine the brain network responsible for the inhibition of automatic imitation have been conducted [25, 26, 33, 51]. Combining these methods and personal trait data may provide deeper insight into the topic.

Because of their simplicity and popularity in the scientific field, we used EQ-SQ scores to assess cognitive traits. However, further study with many different questionnaires, combined with appropriate statistics, may provide a more robust result. Further, despite $\mathrm{mu}$ rhythm suppression being a widely used measure of MNS activity, there are several concerns about its quality. The major claim concerns contamination of alpha wave attenuation related to attention and visual input [21, 23]. Although simultaneous measurement of fMRI and EEG have suggested that mu rhythm is a reliable index of MNS activity, additional study with different methods to assess brain activity is required.

\section{Conclusions}

In conclusion, this study indicated that behavioral and physiological measures of an imitation inhibition task are differentially related to personal cognitive traits. The congruency effect on the reaction time obtained from the imitation inhibition task was negatively correlated with EQ scores, and the physiological index was positively correlated with SQ scores. The application of SDT to the imitation-inhibition paradigm provided a deeper understanding to this field of study. Therefore, the current study indicated that variation in cognition is related to the inhibition of congruency effect produced by finger movements. In addition, it is suggested that the behavioral indices and the $\triangle E R D$ reflect different steps of information processing. Further research with different empathizing-systemizing assessment methods and neurophysiological measures are required in the future.

\section{Abbreviations}

ANOVA: Analysis of variances; EEG: Electroencephalogram; EQ: Empathizing quotient; ERD: Event-related desynchronization; fMRI: Functional magnetic resonance imaging; LC: Left central; MNS: Mirror neuron system; MO: Mid occipital; ROI: Region of interest; SDT: Signal detection theory;

$\mathrm{SQ}$ : Systemizing quotient

\section{Acknowledgements}

We thank Mr. Fujiwara and other laboratory members for their support.

\section{Funding}

This work was supported by the Japan Society for the Promotion of Science (16J04125).

\section{Availability of data and materials}

The datasets used and/or analyzed during the current study are available from the corresponding author on reasonable request.

\section{Authors' contributions}

YN conceived and designed the study, performed the experiments and the statistical analysis, and drafted the manuscript. YI helped to carry out the experiments and analyze the data. $\mathrm{Yl}$ and $\mathrm{SH}$ participated in designing and coordinating the experiment, and helped to draft the manuscript. All authors have read and approved the final manuscript.

\section{Ethics approval and consent to participate}

All participants gave their written informed consent after a complete explanation of this study and before participation. The study was performed in accordance with the guidelines of the Declaration of Helsinki and was approved by the ethics committee of Kyushu University.

\section{Consent for publication}

Not applicable

Competing interests

The authors declare that they have no competing interest.

\section{Publisher's Note}

Springer Nature remains neutral with regard to jurisdictional claims in published maps and institutional affiliations.

\section{Author details}

${ }^{1}$ Graduate School of Integrated Frontier Sciences, Kyushu University, 4-9-1 Shiobaru, Minami-ku, Fukuoka 8158540, Japan. ${ }^{2}$ Research Fellow of the Japan Society for the Promotion of Science, 4-9-1 Shiobaru, Minami-ku, Fukuoka 8158540, Japan. ${ }^{3}$ Faculty of Design, Kyushu University, 4-9-1 Shiobaru, Minami-ku, Fukuoka 8158540, Japan. 
Received: 16 July 2018 Accepted: 10 October 2018

Published online: 29 October 2018

\section{References}

1. Gazzaniga MS. Human the science behind what makes us unique. New York: HaperCollins Publishers; 2008.

2. Decety J, Svetlova M. Putting together phylogenetic and ontogenetic perspectives on empathy. Dev. Cogn. Neurosci. [Internet]. 2012;2:1-24 Elsevier Ltd Available from: http://dx.doi.org/10.1016/j.dcn.2011.05.003.

3. de Waal FBM. The antiquity of empathy. Science (80-. ). [Internet]. 2012;336: 874-876. Available from: https://doi.org/10.1126/science.1220999

4. Baumeister RF, Leary MR. The need to belong: desire for interpersonal attachments as a fundamental human motivation. Psychol. Bull. [Internet]. 1995;117:497-529. Available from: https://doi.org/10.1037/0033-2909.117.3.497

5. Rizzolatti G, Craighero L. THE MIRROR-NEURON SYSTEM. Annu Rev Neurosci [Internet]. 2004;27:169-192. Available from: https://doi.org/10.1146/annurev. neuro.27.070203.144230

6. lacoboni M, Woods RPR, Brass M, Bekkering H, Mazziotta JC, Rizzolatti G, et al. Cortical mechanisms of human imitation. Science (80-. ). 1999;286:2526-8.

7. Kilner JM, Lemon RN. What we know currently about mirror neurons. Curr. Biol. [Internet]. 2013;23:R1057-62 Elsevier Ltd Available from: http://dx.doi. org/10.1016/j.cub.2013.10.051

8. Rizzolatti $\mathrm{G}$, Sinigaglia C. The mirror mechanism: a basic principle of brain function. Nat Rev Neurosci [Internet]. Nature Publishing Group; 2016;17:757765. Available from: https://doi.org/10.1038/nrn.2016.135

9. lacoboni M. Imitation, empathy, and mirror neurons. Annu Rev Psychol [Internet]. 2009;60:653-670. Available from: https://doi.org/10.1146/annurev. psych.60.110707.163604

10. Babiloni C, Del Percio C, Vecchio F, Sebastiano F, Di Gennaro G, Quarato PP, et al. Alpha, beta and gamma electrocorticographic rhythms in somatosensory, motor, premotor and prefrontal cortical areas differ in movement execution and observation in humans. Clin. Neurophysiol. [Internet]. Elsevier; 2016;127:641-54. Available from: https://doi.org/10.1016/j. clinph.2015.04.068

11. Fadiga L, Fogassi L, Pavesi G, Rizzolatti G. Motor facilitation during action observation: a magnetic stimulation study. J Neurophysiol. 1995;73:2608-11.

12. Mukamel R, Ekstrom AD, Kaplan J, lacoboni M, Fried I. Single-neuron responses in humans during execution and observation of actions. Curr. Biol. [Internet]. 2010;20:750-756. Available from: https://doi.org/10.1016/j. cub.2010.02.045

13. Strafella a P, Paus T. Modulation of cortical excitability during action observation: a transcranial magnetic stimulation study. Neuroreport. 2000;11: 2289-92.

14. Catmur C, Walsh V, Heyes C. Associative sequence learning: the role of experience in the development of imitation and the mirror system. Philos. Trans. R. Soc. B Biol. Sci. [Internet]. 2009;364:2369-2380. Available from: https://doi.org/10.1098/rstb.2009.0048

15. Cooper RP, Cook R, Dickinson A, Heyes CM. Associative (not Hebbian) learning and the mirror neuron system. Neurosci. Lett. [Internet]. 2013;540:28-36 Elsevier Ireland Ltd Available from: http://dx.doi.org/10.1016/j.neulet.2012.10.002.

16. Nishimura $Y$, Ikeda $Y$, Suematsu A, Higuchi S. Effect of visual orientation on mu suppression in children: a comparative EEG study with adults. J Physiol Anthropol. 2018:37:16

17. Braadbaart L, Williams JHG, Waiter GD. Do mirror neuron areas mediate mu rhythm suppression during imitation and action observation? Int. J Psychophysiol [Internet]. 2013;89:99-105 Elsevier B.V. Available from: http:// dx.doi.org/10.1016/j.ijpsycho.2013.05.019.

18. Perry A, Bentin S. Does focusing on hand-grasping intentions modulate electroencephalogram $\mu$ and a suppressions? Neuroreport [Internet]. 2010;21: 1050-1054. Available from: https://doi.org/10.1097/WNR.0b013e32833fcb71

19. Takemi M, Masakado Y, Liu M, Ushiba J. Event-related desynchronization reflects downregulation of intracortical inhibition in human primary motor cortex. J Neurophysiol [Internet]. 2013;110:1158-1166. Available from: https://doi.org/10.1152/jn.01092.2012

20. Bowman LC, Bakermans-Kranenburg MJ, Yoo KH, Cannon EN, Vanderwert RE, Ferrari PF, et al. The mu-rhythm can mirror: insights from experimental design, and looking past the controversy. Cortex [Internet]. Elsevier; 2017;96: 121-125. Available from: https://doi.org/10.1016/j.cortex.2017.03.025

21. Hobson HM, Bishop DVM. Mu suppression - a good measure of the human mirror neuron system? Cortex [Internet]. 2016:82:290-310. Available from: https://doi.org/10.1016/j.cortex.2016.03.019
22. Isoda K, Sueyoshi K, Ikeda Y, Nishimura Y, Hisanaga I, Orlic S, et al. Effect of the hand-omitted tool motion on mu rhythm suppression. Front Hum Neurosci [Internet]. Frontiers; 2016;10266. Available from: https://doi.org/10. 3389/fnhum.2016.00266

23. Fox NA, Bakermans-Kranenburg MJ, Yoo KH, Bowman LC, Cannon EN, Vanderwert RE, et al. Assessing human mirror activity with EEG mu rhythm: a meta-analysis. Psychol Bull [Internet]. 2016;142:291-313 Available from: http://doi.apa.org/getdoi.cfm?doi=10.1037/bul0000031.

24. Campbell MEJ, Cunnington R. More than an imitation game: top-down modulation of the human mirror system. Neurosci. Biobehav. Rev. [Internet]. 2017:75:195-202. Available from: https://doi.org/10.1016/j.neubiorev.2017.01.035

25. Brass M, Zysset $S$, von Cramon DY. The inhibition of imitative response tendencies. Neuroimage [Internet]. 2001;14:1416-1423. Available from: https://doi.org/10.1006/nimg.2001.0944

26. Cross KA, lacoboni M. To imitate or not: avoiding imitation involves preparatory inhibition of motor resonance. Neuroimage [Internet]. 2014;91:228-36 Elsevier Inc. Available from: http://dx.doi.org/10.1016/j.neuroimage.2014.01.027.

27. Newman-Norlund RD, van Schie HT, van Zuijlen AMJ, Bekkering $H$. The mirror neuron system is more active during complementary compared with imitative action. Nat Neurosci. 2007;10:817-8.

28. Brass M, Ruby P, Spengler S. Inhibition of imitative behaviour and social cognition. Philos. Trans. R. Soc. B Biol. Sci. [Internet]. 2009;364:2359-2367. Available from: https://doi.org/10.1098/rstb.2009.0066

29. Darda KM, Butler EE, Ramsey R. Functional specificity and sex differences in the neural circuits supporting the inhibition of automatic imitation. J Cogn Neurosci [Internet]. 2018;30:914-933. Available from: https://doi.org/10.1162/jocn_a_01261

30. Campbell MEJ, Mehrkanoon S, Cunnington R. Intentionally not imitating: insula cortex engaged for top-down control of action mirroring. Neuropsychologia [Internet]. 2018;111:241-51 Pergamon. Available from: https://www.sciencedirect.com/science/article/pii/ S0028393218300435?via\%3Dihub

31. Campbell MEJ, Mehrkanoon S, Cunnington R. Intentionally not imitating: insula cortex engaged for top-down control of action mirroring. Neuropsychologia [Internet]. 2018;111:241-51 Available from: https://doi. org/10.1016/j.neuropsychologia.2018.01.037

32. Sowden $\mathrm{S}$, Catmur $\mathrm{C}$. The role of the right Temporoparietal junction in the control of imitation. Cereb Cortex [Internet]. 2015;25:1107-13. Available from: https://doi.org/10.1093/cercor/bht306.

33. Brass $M$, Bekkering $H$, Wohlschläger A, Prinz W. Compatibility between observed and executed finger movements: comparing symbolic, spatial, and imitative cues. Brain Cogn. [Internet]. 2000;44:124-143. Available from: https://doi.org/10.1006/brcg.2000.1225

34. Watanabe R, Higuchi T, Kikuchi Y. Imitation behavior is sensitive to visual perspective of the model: an fMRI study. Exp Brain Res [Internet]. 2013;228: 161-71 Available from: https://doi.org/10.1007/s00221-013-3548-7.

35. Baron-Cohen S. The extreme male brain theory of autism. Trends Cogn Sci. 2002:6:248-54.

36. Wakabayashi A, Baron-Cohen S, Wheelwright S. Individual and gender differences in empathizing and systemizing: measurement of individual differences by the empathy quotient (EQ) and the systemizing quotient (SQ). Japanese J Psychol [Internet]. The Japanese Psychological Association; 2006;77:271-277. Available from: https://doi.org/10.4992/jjpsy.77.271

37. Baron-Cohen S, Wheelwright S. The empathy quotient: an investigation of adults with Asperger syndrome or high functioning autism, and Normal sex differences. J Autism Dev Disord. 2004:34:163-75.

38. Baron-Cohen S, Richler J, Bisarya D, Gurunathan N, Wheelwright S. The systemizing quotient: an investigation of adults with Asperger syndrome or high-functioning autism, and normal sex differences. Philos Trans R Soc B Biol Sci. 2003;358:361-74.

39. Marques-Teixeira J, Barbosa F, Almeida PR. Using signal detection theory indexes for the experimental manipulation of emotional states. Methodology [Internet]. 2009:5:55-59. Available from: https:/doi.org/10.1027/1614-2241.5.2.55

40. Barbosa F, Almeida PR, Ferreira-Santos F, Marques-Teixeira J. Using signal detection theory in the analysis of emotional sensitivity of male recidivist offenders. Crim Behav Ment Heal [Internet]. 2016;26:18-29 Available from: http://doi.wiley.com/10.1002/cbm.1950.

41. Tanner WP, Swets JA. A decision-making theory of visual detection. Psychol Rev [Internet]. 1954;61:401-9 Available from: https://doi.org/10.1037/h0058700.

42. Cross KA, lacoboni M. Neural systems for preparatory control of imitation. Philos. Trans. R. Soc. B Biol. Sci. [Internet]. 2014:369:20130176. Available from: https://doi.org/10.1098/rstb.2013.0176 
43. Delorme A, Makeig S. EEGLAB: an open source toolbox for analysis of single-trail EEG dynamics including independent component analysis. J Neurosci Methods. 2004;134:9-21.

44. R Core Team. R: A language and environment for statistical computing. R Foundation for Statistical Computing [Internet]. Vienna, Austria; 2018. Available from: https://www.r-project.org/.

45. Bernieri FJ. Coordinated movement and rapport in teacher-student interactions. J Nonverbal Behav. 1988;12:120-38.

46. Lafrance $M$, Broadbent $M$. Group rapport: posture sharing as a nonverbal indicator, vol. 1. Thousand Oaks: Gr Organ Stud Sage PublicationsSage CA; 1976. p. 328-33.

47. Leighton J, Bird G, Orsini C, Heyes C. Social attitudes modulate automatic imitation. J Exp Soc Psychol Academic Press. 2010;46:905-10.

48. Cook J, Bird G. Social attitudes differentially modulate imitation in adolescents and adults. Exp Brain Res [Internet]. 2011;211:601-612. Available from: https://doi.org/10.1007/s00221-011-2584-4

49. Bozzacchi C, Spinelli D, Pitzalis S, Giusti MA, Di Russo F. I know what I will see: action-specific motor preparation activity in a passive observation task. Soc Cogn Affect Neurosci [Internet]. 2015;10:783-789. Available from: https://doi.org/10.1093/scan/nsu115

50. Cross K a, Torrisi S, Reynolds Losin EA, lacoboni M. Controlling automatic imitative tendencies: interactions between mirror neuron and cognitive control systems. Neuroimage [Internet]. 2013;83:493-504 Elsevier Inc. Available from: http://dx.doi.org/10.1016/j.neuroimage.2013.06.060

51. de Guzman M, Bird G, Banissy MJ, Catmur C. Self-other control processes in social cognition: from imitation to empathy. Philos Trans R Soc B Biol. Sci. [nternet] 2016;371:20150079 Available from: https:/doi.org/10.1098/rstb.2015.0079.

52. Pineda JA. The functional significance of mu rhythms: translating "seeing" and "hearing" into "doing" Brain Res. Rev. [Internet]. Department of Cognitive Science and Neuroscience, University of California, San Diego, San Diego, CA 92037-0515, United States; 2005; 50:57-68. Available from: https://doi.org/10.1016/j.brainresrev.2005.04.005

53. Oberman LM, McCleery JP, Hubbard EM, Bernier R, Wiersema JR, Raymaekers $R$, et al. Developmental changes in mu suppression to observed and executed actions in autism spectrum disorders. Soc Cogn Affect Neurosci. 2013;8:300-4.

54. Wright DB, Skagerberg EM. Measuring empathizing and systemizing with a large US sample. PLoS One. 2012;7:e31661.

55. Heyes C. Where do mirror neurons come from? Neurosci Biobehav Rev [Internet]. 2010;34:575-83 Available from: https://doi.org/10.1016/j. neubiorev.2009.11.007.

56. Heyes C, Bird G, Johnson H, Haggard P. Experience modulates automatic imitation. Cogn. Brain Res. [Internet]. 2005 [cited 2017 Jun 5];22:233-240. Available from: https://doi.org/10.1016/j.cogbrainres.2004.09.009

Ready to submit your research? Choose BMC and benefit from:

- fast, convenient online submission

- thorough peer review by experienced researchers in your field

- rapid publication on acceptance

- support for research data, including large and complex data types

- gold Open Access which fosters wider collaboration and increased citations

- maximum visibility for your research: over $100 \mathrm{M}$ website views per year

At BMC, research is always in progress.

Learn more biomedcentral.com/submissions 